PAPER • OPEN ACCESS

Development of the Production Process Model Based on the Controllable Input Factors

To cite this article: I Plotnikova et al 2016 IOP Conf. Ser.: Mater. Sci. Eng. 132012023

View the article online for updates and enhancements.
You may also like

- Bending of $\mathrm{CORC}^{\circledR}$ cables and wires: finite
$\frac{\text { element parametric study and }}{\text { experimental validation }}$
V A Anvar, K llin, K A Yagotintsev et al.
- Electron-Positron Pair Production in
$\frac{\text { Strong Fields Characterized by }}{\text { Conversion Energy }}$
lbrahim Sitiwaldi, Zi-Liang Li, et al.
- Incorporating thermoelectric power plant
$\frac{\text { water use into multi-objective optimal }}{\text { power flow }}$
Jacob Kravits, Joseph R Kasprzyk, Kyri
Baker et al.

The Electrochemical Society

Aurvancing solit state e selectrochenical science s tectinology

243rd Meeting with SOFC-XVIII

Boston, MA • May 28 - June 2, 2023

Accelerate scientific discovery!
Learn More \& Register

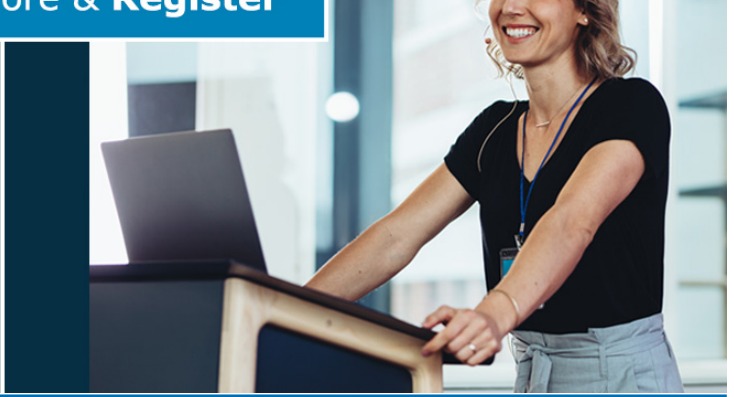

This content was downloaded from IP address 3.85 .5 .30 on $26 / 04 / 2023$ at $08: 40$ 


\title{
Development of the Production Process Model Based on the Controllable Input Factors
}

\author{
I Plotnikova $^{1}$, L Redko $^{1}$, O Titova $^{2}$ and O Chaykovskaya ${ }^{3}$ \\ ${ }^{1}$ Associate Professor, National Research Tomsk Polytechnic University, Tomsk, \\ Russia \\ ${ }^{2}$ Associate Professor, Siberian State University of Geosystems and Technologies, \\ Novosibirsk, Russia \\ ${ }^{3}$ Professor, National Research Tomsk State University, Tomsk, Russia \\ E-mail: inna@tpu.ru
}

\begin{abstract}
The research aims to study noncompliances in the production process, defects in chipboard manufacturing and the related costs. The influence of production process parameters on the parameters of finished products and correlation dependence of considered parameters have been shown. The mathematical model of the multiple-factor production process has been developed.
\end{abstract}

\section{Introduction}

One of the key factors to ensure the enterprise competitiveness is the quality of products. The product quality is determined not by the quality control and sorting based on the principle of compliance, but mostly by manufacturing environment. The level of noncompliances in the production process output can be reduced by control of the process parameters. The dependence of output parameters of the product quality on variations in the process parameters should be known to reduce noncompliances. To determine such dependencies based on investigation of the process behavior is crucial for enterprises aspiring to the reduction of costs, organization of production process, and enhancement of efficiency of the company's activities and competitiveness as a whole [1].

The combination of factors and conditions of production process results in problems with product quality, but consistent changes in the factors and conditions are capable of eliminating noncompliances. Factors include working facilities; the ability of workers to work in a qualitative and efficient manner; work objects. Conditions include the nature of production process, its intensity, rhythm, duration; climatic conditions in industrial premises; industrial interior and design; the nature of material and moral stimuli; forms of organizing the information service and workplace equipment; social and material conditions for workers [2,3].

Investigation of influence of the production process parameters on the quality parameters of finished products enables the quality control during the process of manufacturing. This leads to reduction in losses and costs for noncompliances, including sorting reduction, lower cost of the finished product, costs for utilization of unusable products, compensations and payments to consumers due to the possible delivery of defective products. 
The enterprise manufacturing chipboards urgently needs determination of the level of costs due to the occurrence of defective products in the production process, and investigation of types and causes of these costs [4].

The aim of the research was to determine the environment of the chipboard manufacturing process using the method of planning the experiment [5-9] at the stage of the wood chip cover formation. The parameter characterizing the process of production is the chipboard density $\left(\mathrm{kg} / \mathrm{m}^{3}\right)$. According to the enterprise requirements, the optimum values of density correspond to the limit values of $(680-700)$ $\left(\mathrm{kg} / \mathrm{m}^{3}\right)$.

\section{Research description}

Before the development of a mathematical model of the process, a priori information was considered by analyzing the chipboard production process using statistical methods of control. As a result, losses attributable to the issue of defective products were estimated, stages of the chipboard production process with the greatest number of defective boards were defined, types of defects and most common defects were identified in accordance with the rule 80/20. "Short and friable boards" refer to these defects. The causes of their formation in the production process were identified in the study of these types of defects.

The chipboard density $\left(\mathrm{kg} / \mathrm{m}^{3}\right)$ was defined as the main parameter of chipboard quality. It was revealed that the wood chip cover formation is the stage of the process with the greatest number of defects. The parameters that affect the chipboard quality at this stage and can be regulated during the production process were identified. The parameters are fixed in the process maps by the laboratory technicians every two hours. The parameters are as follows: wood chip moisture, \%; resinification of the board inner layer, \%; resinification of the board outer layer, \%; rate of the wood chip cover formation, $\mathrm{mm} / \mathrm{s}$; ratio of layer,\%; weight of the wood chip cover, $\mathrm{kg}$; pressing temperature, ${ }^{\circ} \mathrm{C}$; pressure on the press, $\mathrm{kgc} / \mathrm{cm}^{2}$.

The correlation dependence between the parameters was calculated to reduce the number of considered parameters. If the correlation coefficient ( $\mathrm{r}$ ) evidences the presence of correlated values, one of the values can be excluded from consideration. The evaluation of correlation dependence of the considered production parameters were presented in pairs in the form of scatter diagrams in figure 1 .

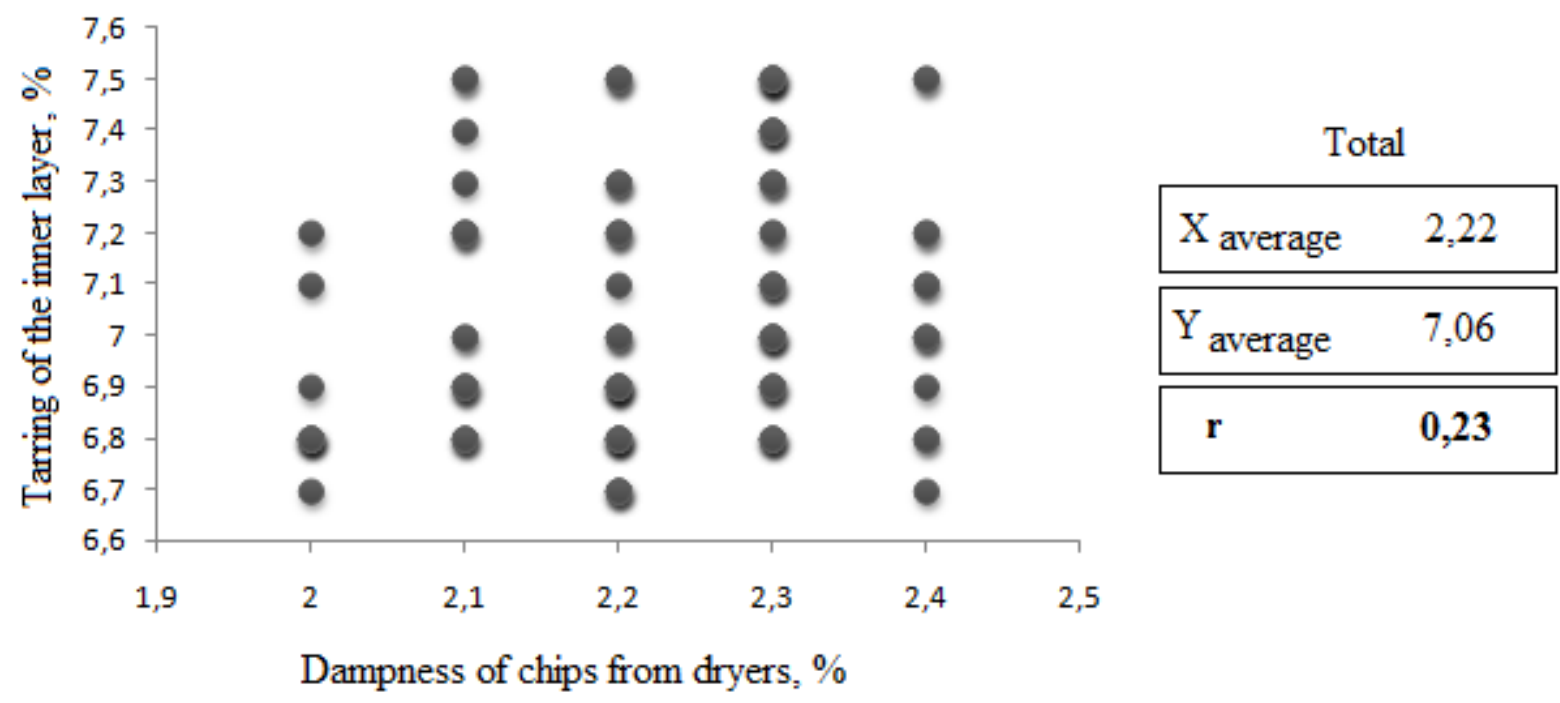

Figure 1. Correlation dependence between the chipboard inner layer and wood chip moisture.

The absence of tolerable correlation connection indicates that all parameters of the production process should be included in the experiment. 
After considering a priori information, the object of consideration was defined in the form of "black box". At this stage, all investigated parameters of the chipboard production process were divided into two groups: factors such as chip moisture, resinification of the inner layer, resinification of the outer layer, and random effects such as rate of the wood chip cover formation, ratio of layers, weight of the cover, pressing temperature, pressure on the press. It was decided to develop a mathematical model for the stage of the wood chip cover formation because the largest qualitative and quantitative amount of defective products is formed at this stage. The quality indicator, namely the board density was chosen as a response.

The next stage of the research is to collect data on the density parameter under different conditions of the production process. The mechanisms and optimum parameters of the chipboard manufacturing can be determined based on these data.

Divide all the parameters into three groups:

- Chip moisture, ratio of layers, pressing temperature.

- Resinification of the inner layer, pressure on the press.

- Resinification of the outer layer, rate of the wood chip cover formation, weight of the cover.

The model for the stage of chipboard manufacturing, that is wood chip cover formation is shown in figure 2 .

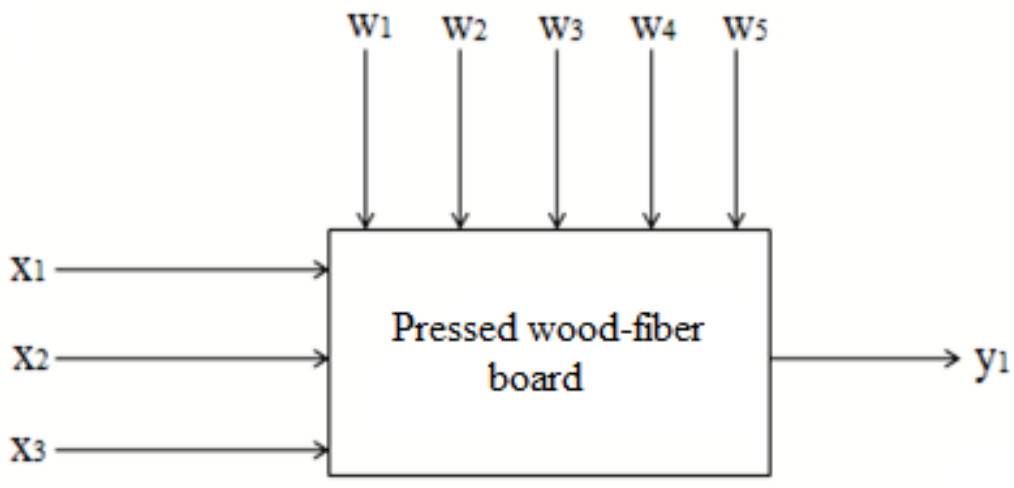

Figure 2. Model of the multi-factor process of chipboard manufacturing.

The factors are designated as: $\mathrm{x}_{1}$ is chip moisture, $\% ; \mathrm{x}_{2}$ is resinification of the inner layer, $\% ; \mathrm{x}_{3}$ is resinification of the outer layer, $\%$.

All other parameters correspond to random effects: $\mathrm{w}_{1}$ is rate of wood chip cover formation, $\mathrm{mm} / \mathrm{s}$; $\mathrm{w}_{2}$ is ratio of layers, $\% ; \mathrm{w}_{3}$ is weight of the cover, $\mathrm{kg} ; \mathrm{w}_{4}$ is pressing temperature, ${ }^{\circ} \mathrm{C} ; \mathrm{w}_{5}$ is pressure on the press, $\mathrm{kgc} / \mathrm{cm}^{2}$.

The quality index, namely density $y\left(\mathrm{~kg} / \mathrm{m}^{3}\right)$ was taken as a response of the chipboard manufacturing.

The random effects such as rate of the wood chip cover formation, ratio of layers, weight of the cover, pressing temperature, pressure on the press can be varied at this stage. It is impossible to change the factors such as chip moisture, resinification of the inner and outer layers at this stage. They come to the process input with concrete values.

Based on a priori information, the values within which each factor may change its values. 1.

The principle level and variability interval determined for each of the factors are presented in table

All possible factors are determined by the equation 1

$$
N=p^{k}
$$

where $\mathrm{p}$ is the number of levels; $\mathrm{k}$ is the number of factors.

Each of the eight factors varies at two levels; therefore equation 1 takes the form equation 2 :

$$
N=2^{k} \text {. }
$$


IV International Conference on Modern Technologies for Non-Destructive Testing

IOP Publishing IOP Conf. Series: Materials Science and Engineering 132 (2016) 012023 doi:10.1088/1757-899X/132/1/012023

The factors are divided into three groups; the experiment is to be carried out for each of the groups.

As an example, consider the experimental plan for the first group of factors: chip moisture, ratio of layers, pressing temperature (table 2).

Table 1. Levels of factor variability.

\begin{tabular}{lllll}
\hline \multirow{2}{*}{ Factors } & Factor levels & & & $\begin{array}{l}\text { Variability } \\
\text { interval }\end{array}$ \\
\cline { 2 - 5 } & Lower level $\ll-1 »$ & Zero level $\ll 0 »$ & Upper level «+1» & 0.25 \\
\hline $\mathrm{x}_{1}$ & 2 & 2.25 & 2.5 & 0.4 \\
\hline $\mathrm{x}_{2}$ & 6.7 & 7.1 & 7.5 & 0.65 \\
\hline $\mathrm{x}_{3}$ & 10,9 & 11.55 & 12.2 & 50 \\
\hline $\mathrm{w}_{1}$ & 320 & 370 & 420 & 0.55 \\
\hline $\mathrm{w}_{2}$ & 20 & 20.55 & 21.1 & 5.5 \\
\hline $\mathrm{w}_{3}$ & 125 & 130.5 & 136 & 1.5 \\
\hline $\mathrm{w}_{4}$ & 195 & 196.5 & 198 & 29 \\
\hline $\mathrm{w}_{5}$ & 192 & 221 & 250 & \\
\hline
\end{tabular}

Table 2. Extended matrix of planning the experiment of $2^{3}$ type.

\begin{tabular}{|r|r|r|r|r|c|c|c|}
\hline $\mathrm{x}_{01}$ & $\mathrm{x}_{1}$ & $\mathrm{w}_{2}$ & $\mathrm{w}_{4}$ & $\mathrm{x}_{1} \cdot \mathrm{w}_{2}$ & $\mathrm{w}_{2} \cdot \mathrm{w}_{4}$ & $\mathrm{x}_{1} \cdot \mathrm{w}_{4}$ & $\mathrm{x}_{1} \cdot \mathrm{w}_{2} \cdot \mathrm{w}_{4}$ \\
\hline+1 & +1 & +1 & +1 & +1 & +1 & +1 & +1 \\
\hline+1 & -1 & +1 & +1 & -1 & +1 & -1 & -1 \\
\hline+1 & +1 & -1 & +1 & -1 & -1 & +1 & -1 \\
\hline+1 & -1 & -1 & +1 & +1 & -1 & -1 & +1 \\
\hline+1 & +1 & +1 & -1 & +1 & -1 & -1 & -1 \\
\hline+1 & -1 & +1 & -1 & -1 & -1 & +1 & +1 \\
\hline+1 & +1 & -1 & -1 & -1 & +1 & -1 & +1 \\
\hline+1 & -1 & -1 & -1 & +1 & +1 & +1 & -1 \\
\hline
\end{tabular}

\section{Summary}

Thus, depending on the input factor value, for instance, chip moisture at the input stage of chipboard manufacturing, namely the formation of wood chip cover, the necessary values of random effects such as correlation of layers and pressing temperature may be chosen so that the chipboard density will correspond to the required values.

\section{References}

[1] Deming W E 1986 Out of the Crisis (Massachusetts Institute of Technology, Center for Advanced Engineering Study)

[2] Neave H R 1987 Journal of the Royal Statistical Society. Series D (The Statistician) Special Issue: Industry, Quality and Statistics 36 (5) 561570

[3] Evant J R 2005 Total Quality: Management, Organization and Strategy (South-Western College Publishing)

[4] Vasendina E A et al 2015 IOP Conference Series: Materials Science and Engineering 81 (1) 012070 DOI:10.1088/1757-899X/81/1/012070

[5] Kumje $\mathrm{H}$ et al 1991 Statistical method to improve quality (Moscow)

[6] Montgomery D C 2012 Reliability and Maintainability Symposium URL http://www.reliasoft.com/pubs/2012_RAMS_design_of_experiments_and_data_analysis.pdf

[7] Bordunov S V et al 2016 Journal of Physics: Conference Series 671 (1) 012009 DOI: 10.1088/1742-6596/671/1/012009

[8] Surzhikov A.P et al 2010 Journal of Thermal Analysis and Calorimetry 102 (3) $883-887$

[9] Surzhikov A P et al 2012 Journal of Thermal Analysis and Calorimetry 108 (3) 1207-1212 